\title{
Upper extremity impairments in women with or without lymphedema following breast cancer treatment
}

\author{
Betty Smoot • Josephine Wong • Bruce Cooper • \\ Linda Wanek • Kimberly Topp • Nancy Byl • \\ Marylin Dodd
}

Received: 23 August 2009 / Accepted: 7 February 2010/Published online: 7 April 2010

(C) The Author(s) 2010. This article is published with open access at Springerlink.com

\begin{abstract}
Introduction Breast-cancer-related lymphedema affects $\sim 25 \%$ of breast cancer (BC) survivors and may impact use of the upper limb during activity. The purpose of this study is to compare upper extremity (UE) impairment and activity between women with and without lymphedema after BC treatment.

Methods 144 women post BC treatment completed demographic, symptom, and Disability of Arm-Shoulder-Hand (DASH) questionnaires. Objective measures included Purdue pegboard, finger-tapper, Semmes-Weinstein monofilaments, vibration perception threshold, strength, range of motion (ROM), and volume.

Results Women with lymphedema had more lymph nodes removed $(p<.001)$, more UE symptoms $(p<.001)$, higher $\operatorname{BMI}(p=.041)$, and higher DASH scores (greater limitation) $(p<.001)$. For all participants there was less strength (elbow
\end{abstract}

\author{
B. Smoot $\cdot$ K. Topp $\cdot$ N. Byl \\ Department of Physical Therapy and Rehabilitation Science, \\ University of California San Francisco, \\ San Francisco, CA, USA \\ J. Wong $\cdot$ B. Cooper $\cdot$ M. Dodd \\ Department of Physiological Nursing, \\ University of California San Francisco, \\ San Francisco, CA, USA \\ L. Wanek \\ Graduate Program in Physical Therapy, \\ San Francisco State University, \\ San Francisco, CA, USA \\ B. Smoot $(\square)$ \\ 18787 Gillman Drive, \\ Sonoma, CA 95476, USA \\ e-mail: betty.smoot@ucsf.edu
}

flexion, wrist flexion, grip), less shoulder ROM, and decreased sensation at the medial upper arm $(p<.05)$ in the affected UE. These differences were greater in women with lymphedema, particularly in shoulder abduction ROM $(p<.05)$. Women with lymphedema had bilaterally less elbow flexion strength and shoulder ROM $(p<.05)$. Past diagnosis of lymphedema, grip strength, shoulder abduction ROM, and number of comorbidities contributed to the variance in DASH scores $\left(R^{2}\right.$ of $\left.0.463, p<.001\right)$.

Implications for cancer survivors UE impairments are found in women following treatment for BC. Women with lymphedema have greater UE impairment and limitation in activities than women without. Many of these impairments are amenable to prevention measures or treatment, so early detection by health care providers is essential.

Keywords Lymphedema · Breast cancer - Movement . Impairment · Upper extremity

\section{Introduction}

Treatment for breast cancer has improved dramatically over the last two decades. While these treatments have significantly increased the 5 year survival rates, they are not without lasting adverse effects. Currently there are over two million breast cancer survivors in the United States [1-3] and a considerable number of these women have or will develop complications, such as lymphedema or post-treatment pain, as a result of their treatment. It is our hypothesis that following breast cancer treatment, women will demonstrate upper extremity physical impairment, and these impairments will contribute to limitations in activities requiring use of the affected upper limb. Moreover, we hypothesize that those women who develop breast-cancer-related lymphedema will demonstrate 
greater upper extremity impairment than women who do not develop lymphedema.

Breast cancer treatments include surgery, radiation, and systemic therapies and each is associated with short and long term sequelae. Chemotherapy, for example, is known to induce neuropathy, impaired concentration and memory, and generalized fatigue [4-6]. Chemotherapy plus radiation therapy after axillary node dissection have been associated with chronic pain, particularly in the ipsilateral arm [7]. Local treatments such as axillary dissection or radiation therapy following surgical excision of the tumor have been associated with regional physical dysfunction and increased incidence of long term arm morbidity, including impaired shoulder mobility and lymphedema [8, 9]. For example, shoulder range of motion is limited in up to $45 \%$ of patients who have sentinel node biopsy, and $86 \%$ of patients who have undergone axillary clearance [10].

Breast-cancer-related lymphedema develops in $5 \%$ to $42 \%$ of women following breast cancer treatment, dependent, in part, on the aggressiveness of treatment [11, 12]. Lymphedema is the accumulation of protein rich interstitial fluid as a result of impaired lymphatic function [13]. Lymphedema related to breast cancer treatment may result from surgical removal of lymph nodes and lymphatic drainage pathways. Further damage to the lymphatic system may result from soft tissue fibrosis following inflammation, infection, or radiation. Of significant importance to patients, breast-cancer-related lymphedema is an impairment which can adversely affect upper extremity function [14-16].

Though several recent studies have investigated upper extremity function in women following breast cancer treatment, none have specifically compared objective measures of upper extremity physical impairments in women with lymphedema and those without. The primary aim of the present study is to compare differences in upper extremity impairment between women who have developed lymphedema after breast cancer treatment and those who have not developed lymphedema. Secondarily, we seek to determine the contribution of impairments to self-reported limitations in activities requiring use of the affected upper extremity. Definitions of impairment and activity are based on the World Health Organization's International Classification of Functioning, Disability and Health Model. Impairments describe physical limitations in body structures and physiological functions, and activity limitations describe difficulties executing a task or action [17].

Many of the complications arising from breast cancer treatment go unrecognized and few of these women are referred for rehabilitation [18]. If there are known and predictable impairments in women after breast cancer treatment, then early assessment and rehabilitation interventions can be implemented to decrease pain, diminish losses in flexibility and strength, and minimize restrictions in activity.

\section{Methods}

Participants

Women, with and without lymphedema, who had completed active breast cancer treatment at least 6 months previously, were recruited. The women were required to be at least 18 years of age, and able to read, speak, and understand English. Women were excluded for bilateral breast cancer, current upper extremity infection, lymphangitis, pre-existing lymphedema, pre-existing neuromuscular or musculoskeletal conditions that would affect local upper extremity testing, or current recurrence of breast cancer. Study participants were recruited through the National Lymphedema Network website, San Francisco Bay area hospitals, San Francisco Bay area breast cancer or lymphedema support groups, and breast cancer conferences.

One hundred and forty eight women completed testing. Of those, three were found to have bilateral mastectomies and one had a total shoulder replacement. These four were excluded from data analysis. The study was approved by the UCSF Committee on Human Research and the Clinical and Translational Science (CTSI) Clinical Research Center Advisory Committee. Written informed consent was obtained from all participants prior to testing.

\section{Procedures}

This study utilized a cross-sectional design. All participants attended a single evaluation session, during which all testing occurred. Both upper extremities were assessed. Testing was completed by one investigator (BS), a physical therapist with over 20 years of experience. All testing was performed in the UCSF CTSI Clinical Research Center.

Fine motor skills were assessed using the standardized Purdue Pegboard (North Coast Medical, Morgan Hill, CA) and the Finger Tapper Test (Psychological Assessment Resources, Inc, Lutz, FL). Strength was assessed using hand held dynamometers. Participants were instructed to squeeze with maximal effort for the grip tests. Strength scores were obtained for shoulder abduction, elbow flexion, and wrist flexion using the MicroFET2 dynamometer (Hoggan MicroFET2 Muscle Tester, Model 7477, Pro Med Products, Atlanta, GA). Three grip tests were performed: full grip using a hand dynamometer (North Coast Medical, Morgan Hill, CA), key grip (lateral opposition) using a pinch gauge (North Coast Medical, Morgan Hill, CA), and pinch grip (terminal opposition or 3point chuck) using the MicroFET2. Three trials of each strength test were performed, and a mean was calculated for each test. Additionally, a combined strength score was calculated as the sum of all strength scores for each upper extremity. 
A goniometer was used to measure ranges of motion (ROM) of the upper extremities. Shoulder flexion, shoulder abduction, shoulder external rotation, elbow flexion and extension, wrist flexion and extension, and flexion of the proximal interphalangeal joint of digit two were measured following standardized procedures reported by Norkin [19]. In addition to individual joint measurements, an overall summed ROM score was calculated for each upper extremity.

Semmes-Weinstein monofilaments (North Coast Medical, Morgan Hill, CA) were used to assess tactile sensitivity of the upper extremities. Test locations were the inner and outer aspects of the arm and forearm, the dorsal aspect of first web space of the hand, the radial aspect of the 2nd digit distal phalanx, and the ulnar aspect of the 5th digit distal phalanx. Each region was tested beginning with the smallest diameter monofilament $(2.83 ; 0.07 \mathrm{~g}$ force) and progressed to successively larger diameter monofilaments, until 5 of 5 correct responses were obtained. Vibration Perception Threshold (VPT) was determined using the BioThesiometer (Bio-Medical Instrument Company, Newbury, Ohio). The pad of each distal phalanx, the radial styloid, and medial epicondyle were assessed. The Bio-Thesiometer probe was placed on the test area and the amplitude increased from zero until the participant reported feeling vibration.

Circumferential assessment and bioimpedance were employed to objectively assess upper extremity limb volume. A flexible tape measure was used to measure circumference of each upper extremity at the ulnar styloid, designated as " 0 " centimeters, and at $10 \mathrm{~cm}$ intervals proximal to " 0 " to a maximum of $40 \mathrm{~cm}$. Hand circumference was measured at the metacarpophalangeal joints and $2 \mathrm{~cm}$ proximally. Volume was calculated from circumference measures using the formula for volume of a truncated cone, $\mathrm{V}=1 / 12 \Pi \sum \mathrm{h}\left(\mathrm{C}_{1}{ }^{2}+\mathrm{C}_{1} \mathrm{C}_{2}+\mathrm{C}_{2}{ }^{2}\right)$, where $\mathrm{h}$ is the length of each measured segment and $\mathrm{C}$ is the circumference at each end of that segment [20]. The Impedimed measurement system (SPF7, Garden City, Australia) was used to measure upper extremity impedance to an alternating electrical current which provided information about fluid distribution in specific regions of the body. Electrodes were placed on the dorsum of the hands, wrists, feet and ankles. The participants were instructed to lie supine for 10 min with no pillows, arms at sides and lower extremities flat and slightly abducted [21].

A demographic questionnaire was used to collect information on age, health, income, ethnicity, menopausal status, performance and activity status, occupation, and health status. Information regarding comorbidities was obtained. Twelve comorbidities were included in the comorbidity listing: heart disease, high blood pressure, lung disease, diabetes, stomach disease or ulcer, urinary tract disorders/kidney disease, liver or gallbladder disease, anemia or other blood disease, depression, osteoarthritis, rheumatoid arthritis, and back pain/problems. Additional questionnaires were completed by the participants to collect information regarding symptoms in the affected breast, symptoms in the upper extremity on the side of the surgery, and general symptom experience.

All participants completed the Disabilities of Arm, Shoulder, and Hand (DASH). The DASH, developed by the American Academy of Orthopedic Surgeons, is a selfreport questionnaire which measures upper limb symptoms and ability to perform common functional activities in people with musculoskeletal disorders of the upper extremity [22]. Test-retest reliability for the DASH has been reported as $r=0.96$ [23]. The questionnaire has 30 items with responses ranging from one to five. Scores are typically converted to 0 to 100 with higher scores reflective of greater disability. The first 21 items are questions in which the individual rates their ability ("no difficulty, mild difficulty, moderate difficulty, severe difficulty or unable") to perform specific activities, such as ability to turn a key, prepare a meal, or make a bed. Two items ask questions regarding the extent to which the upper extremity impairment results in limitations in social activities or activities of daily living. Of the remaining questions regarding upper limb function, five pertain to severity of symptoms, one to sleep interference, and the last to feelings of confidence or usefulness. In reference to the International Classification of Functioning, Disability and Health Model, Dixon et al. [24] report the DASH contains five impairment items, 19 activity limitations, and three participation restriction items.

\section{Data analysis}

Sample size estimate of 120 participants was determined prospectively, based on an alpha level of 0.05 , and power of 0.80. This sample size estimate was based on an estimated correlation coefficient of 0.25 for regression analysis.

Statistical analyses were performed using SPSS statistical software (version 16, SPSS Inc, Chicago, IL). Means and standard deviations for interval data were obtained and unpaired t-tests for significance of differences were performed for normally distributed data. Mann-Whitney ranked sum analysis was used for non-normally distributed interval data. Chi square was used to assess significance of differences in proportions for nominal and categorical variables. To compare interlimb differences between women with lymphedema and those without, analysis of variance (ANOVA) was carried out for within and between group differences.

Regression analysis was used to evaluate the contribution of independent variables of theoretical interest to the 
outcome measure. Multiple linear regression was selected for normally distributed interval data. The DASH was used as the dependent variable. Based on the Item Response Theory method, raw DASH scores were converted to logit scores (the natural $\log$ of the probability of obtaining a particular set of responses versus the probability of not obtaining that set of responses). This analysis allowed conversion of the raw DASH scores to an authentic interval scale.

\section{Results}

Participant characteristics

Results of 144 women were included. Of those, 73 reported a previous diagnosis of lymphedema. Characteristics for study participants are summarized in Table 1 . The women with lymphedema demonstrated significantly higher body mass index, greater arm volume, more years since diagnosis of breast cancer, greater numbers of women who had had node dissection, and greater number of nodes removed. During the 3 months prior to testing, more women in the Lymphedema group reported symptoms of pain, heaviness, ache, or strange sensations in the affected arm (68\%) than in the Non-lymphedema group (39\%).

Type of breast cancer surgery was dichotomized to breast conserving surgery (lumpectomy, segmentectomy, quadrantectomy) and mastectomy (simple, modified radical, or radical). No differences in the number of women were found between groups for radiation, chemotherapy, or type of breast surgery. There were also no differences between groups in numbers of medical comorbidities. Ninety percent of the women had three or fewer comorbidities. Overall, the most commonly reported comorbidities were back pain $(n=46)$, depression $(n=34)$, and high blood pressure $(n=33)$.

The difference in DASH scores between the 2 groups is presented in Table 2. Women with lymphedema scored higher on the DASH than the women without lymphedema. A higher DASH score is indicative of relatively greater limitation.

Table 1 Characteristics of participants, grouped by self-report of lymphedema diagnosis

\begin{tabular}{|c|c|c|c|c|c|c|}
\hline Characteristics & $\begin{array}{l}\text { All participants } \\
n=144\end{array}$ & $\begin{array}{l}\text { Non- } \\
\text { Lymphedema } \\
n=71\end{array}$ & $\begin{array}{l}\text { Lymphedema } \\
n=73\end{array}$ & $\begin{array}{l}\text { Difference in } \\
\text { means }(\mathrm{sd})\end{array}$ & $\begin{array}{l}95 \% \text { confidence } \\
\text { interval }\end{array}$ & Sig. $(p)$ \\
\hline Age (years) & $56.33(9.44)$ & $55.17(8.76)$ & $57.47(9.98)$ & $2.30(1.57)$ & $(-5.39,0.80)$ & $0.15^{\mathrm{a}}$ \\
\hline Body mass index & $26.4(5.54)$ & $25.45(4.63)$ & $27.33(6.22)$ & $1.88(0.91)$ & $(-3.68,-0.08)$ & $0.04^{\mathrm{a}}$ \\
\hline Arm volume difference $(\mathrm{ml})$ & $109.9(243.21)$ & $-7.9(72.61)$ & $224.5(292.16)$ & $-232.34(35.26)$ & $(-302.5,-162.2)$ & $<0.001^{\mathrm{a}}$ \\
\hline Affected side Right/Left & $67 / 77$ & $29 / 42$ & $38 / 35$ & & & $0.18^{\mathrm{b}}$ \\
\hline Dominant UE R/L/ambidext. & $130 / 11 / 3$ & $64 / 5 / 2$ & $66 / 6 / 1$ & & & $0.81^{\mathrm{b}}$ \\
\hline Affected side $=$ Dominant side & 71 & 33 & 38 & & & $0.50^{\mathrm{b}}$ \\
\hline Years of education & $16.69(2.71)$ & $17.04(2.48)$ & $16.33(2.98)$ & $0.71(0.45)$ & $(-0.18,1.60)$ & $0.12^{\mathrm{a}}$ \\
\hline Days/week of exercise & $3.41(1.72)$ & $3.51(1.64)$ & $3.31(1.80)$ & $0.21(0.29)$ & $(-0.37,0.77)$ & $0.48^{\mathrm{a}}$ \\
\hline No. of women working for pay & 85 & 41 & 44 & & & $0.76^{\mathrm{b}}$ \\
\hline Years since breast cancer diagnosis & $6.17(5.35)$ & $4.94(4.06)$ & $7.37(6.15)$ & $2.43(0.87)$ & $(-4.15,-0.72)$ & $0.01^{\mathrm{a}}$ \\
\hline \multicolumn{7}{|l|}{ No. of women who had: } \\
\hline $\mathrm{BCS}^{\mathrm{c}}$ & 82 & 39 & 43 & & & $0.63^{\mathrm{b}}$ \\
\hline Mastectomy & 62 & 32 & 30 & & & \\
\hline Sentinel lymph node biopsy & 93 & 54 & 39 & & & $0.01^{b}$ \\
\hline Axillary lymph node dissection & 108 & 46 & 62 & & & $<0.005^{\mathrm{b}}$ \\
\hline No. of nodes removed & $10.99(7.48)$ & $8.59(6.43)$ & $13.39(7.73)$ & $4.80(1.20)$ & $(-7.18,-2.43)$ & $<0.001^{\mathrm{a}}$ \\
\hline No. who received radiation therapy & 107 & 49 & 58 & & & $0.15^{\mathrm{b}}$ \\
\hline No. who received chemotherapy & 101 & 48 & 53 & & & $0.51^{\mathrm{b}}$ \\
\hline $\begin{array}{l}\text { No. who received prior treatment for } \\
\text { lymphedema }\end{array}$ & 81 & 15 & 66 & & & $<0.001^{\text {b }}$ \\
\hline
\end{tabular}

a independent t-tests for differences in means

${ }^{\mathrm{b}}$ Chi square

${ }^{\mathrm{c}} \mathrm{BCS}$ : breast conserving surgery

Bold indicates statistical significance 
Table 2 DASH scores

\begin{tabular}{|c|c|c|c|c|c|}
\hline & \multicolumn{2}{|c|}{ Non-lymphedema group } & \multicolumn{2}{|c|}{ Lymphedema group } & \multirow[t]{2}{*}{ Difference in means (Mann Whitney U) } \\
\hline & Mean (SD) & Median (range) & Mean (SD) & Median (range) & \\
\hline \multicolumn{6}{|l|}{ DASH } \\
\hline (0-100 scale) & $\begin{array}{l}8.67 \\
(12.63)\end{array}$ & $\begin{array}{l}3.67 \\
(0-7.8)\end{array}$ & $\begin{array}{l}18.48 \\
(17.30)\end{array}$ & $\begin{array}{l}14.17 \\
(1-76.7)\end{array}$ & $p<.001$ \\
\hline
\end{tabular}

Bold indicates statistical significance

\section{Differences between sides}

Significant differences in strength, range of motion, and sensation were found between the affected and unaffected upper extremities, and between patients with and without lymphedema. Assessment of fine motor skills using the Purdue Pegboard and the Finger Tapper yielded no significant differences between upper extremities or lymphedema groups.

Paired t-tests were performed to assess the differences between the affected and unaffected sides for each group. Results are summarized in Table 3. In the Non-lymphedema group, the affected side demonstrated less shoulder abduction strength, and less range of motion of shoulder flexion, abduction, and external rotation, and the overall ROM score $(p<0.05)$ compared to the unaffected side. No other differences between sides were observed in the Nonlymphedema group. For the Lymphedema group, the affected side had less strength in elbow flexion, wrist flexion, and 2 of the 3 grip tests, which resulted in an overall decrease in upper extremity strength compared to the unaffected side. There was less sensitivity to SemmesWeinstein monofilament testing at the medial aspect of the arm, medial forearm, and index finger in the Lymphedema group. In addition, there was less ROM of the affected shoulder (flexion, abduction, and ER), wrist (flexion), and index proximal interphalangeal joint (flexion); and a lower overall ROM score $(p<0.05)$. The largest differences were seen in shoulder abduction. Analysis of variance revealed additional within and between group differences. Bilaterally, women with lymphedema had less elbow flexion strength, and less ROM in shoulder flexion, abduction, external and internal rotation, elbow extension, and index proximal interphalangeal flexion compared to the women without lymphedema. These differences were most pronounced in shoulder abduction ROM (Fig. 1). Moreover, the differences between affected and unaffected sides were greater in the women with lymphedema than in the women without lymphedema in elbow flexion strength, in 1 of 3 grip measures, in ROM (shoulder flexion, abduction, wrist flexion, and index proximal interphalangeal flexion) and in 4 of the 7 regions tested for light touch. The loss of range of motion in shoulder abduction on the affected side in the Lymphedema group was twice the loss of that seen in the Non-lymphedema group (Fig. 1). Table 4 summarizes significance levels for the within subjects and between groups differences.

\section{Regression analysis}

Multiple linear regression was used to evaluate the contribution of the predictor variables to variance in the DASH scores. Correlation matrices were constructed for three thematic sets of predictor variables: demographic and symptom, objective measures of limb volume, and objective measures of UE impairments. To screen for predictors to use in building the multiple linear regression model, predictor variable candidates within thematic sets were evaluated to identify those that correlated with the DASH (the dependent variable) at $r>0.20(p<0.01)$. This level of correlation was chosen based on previously reported correlations between the DASH and various upper extremity objective measures [25]. A correlation of 0.20 represents $4 \%$ of the shared variance. The DASH scores were then regressed on the predictors within each thematic set that met the $>0.20$ criterion. Those predictors in the model that failed to satisfy alpha $<0.1$ criterion were identified and progressively removed from the model, beginning with the variable with the highest $p$ value. For the demographic/ symptom variable set, predictor variables of interest consisted of age, hand dominance, if the dominant side was the affected side, anthropometric characteristics, social support, work history, exercise history, income, education, comorbidities, past diagnosis of lymphedema, breast symptoms, and upper extremity symptoms. Predictor variables of significance in the model were number of comorbidities $(p<0.001)$, subjective report of lymphedema $(p=0.012)$, and pain severity $(p=0.020)$. No predictors of significance were found in the variable set of objective measures of volume. Significant predictors in the UE impairment set consisted of full grip strength on the affected side $(p=$ 0.001 ), and shoulder abduction ROM on the affected side $(p=0.003)$. The DASH was then regressed on the five final predictors from the 3 thematic sets. The predictors again 
Table 3 Comparison of differences in upper extremity measures for women without and with lymphedema

\begin{tabular}{|c|c|c|c|c|c|c|}
\hline \multirow[b]{3}{*}{ UE measures } & \multicolumn{3}{|c|}{ Non lymphedema group $n=71$} & \multicolumn{3}{|c|}{ Lymphedema group $n=73$} \\
\hline & \multicolumn{3}{|c|}{ Unaffected arm versus affected arm } & \multicolumn{3}{|c|}{ Unaffected arm versus affected arm } \\
\hline & $\begin{array}{l}\text { Unaffected } \\
\text { Mean (SD) }\end{array}$ & $\begin{array}{l}\text { Affected } \\
\text { Mean (SD) }\end{array}$ & Mean diff $(95 \% \mathrm{CI})$ & $\begin{array}{l}\text { Unaffected } \\
\text { Mean (SD) }\end{array}$ & $\begin{array}{l}\text { Affected } \\
\text { Mean (SD) }\end{array}$ & Mean diff $(95 \% \mathrm{CI})$ \\
\hline Purdue Pegboard time(sec) & $80.2(8.1)$ & $80.6(12.3)$ & $-0.4(-3.0,2.2)$ & $82.4(10.4)$ & $82.8(12.1)$ & $-0.3(-3.1,2.4)$ \\
\hline Finger Tapper (no. of taps) & $44.5(7.6)$ & $45.4(7.0)$ & $-0.9(-2.3,0.6)$ & $43.0(7.5)$ & $43.5(6.9)$ & $-0.5(-2.1,1.1)$ \\
\hline Shoulder $\mathrm{ABD}^{\mathrm{b}}$ strength $\mathrm{kg}$ & $12.5(2.4)$ & $12.1(2.6)$ & $0.4(0.03,0.8)^{\mathrm{a}}$ & $11.8(2.5)$ & $11.5(4.6)$ & $0.3(-0.6,1.2)$ \\
\hline Elbow flexion strength & $20.9(4.0)$ & $20.9(4.2)$ & $-0.01(-0.4,0.4)$ & $19.6(3.7)$ & $18.5(3.8)$ & $1.1(0.6,1.5)^{\mathrm{a}}$ \\
\hline Wrist flexion strength & $9.4(2.2)$ & $9.6(2.2)$ & $-0.2(-0.5,0.1)$ & $8.9(2.2)$ & $9.4(2.2)$ & $-0.4(-0.8,-0.1)^{\mathrm{a}}$ \\
\hline Grip strength & $27.5(7.0)$ & $26.6(7.1)$ & $0.9(-0.02,1.8)$ & $26.6(6.4)$ & $25.2(6.2)$ & $1.4(0.3,2.5)^{\mathrm{a}}$ \\
\hline Key grip strength & $5.6(1.5)$ & $5.6(1.6)$ & $0.1(-0.2,0.4)$ & $5.5(1.6)$ & $5.3(1.4)$ & $0.2(-0.9,0.5)$ \\
\hline 3 point chuck grip & $6.5(1.7)$ & $6.7(1.8)$ & $-0.2(-0.5,0.1)$ & $6.7(1.8)$ & $6.3(1.7)$ & $0.4(0.1,0.7)^{\mathrm{a}}$ \\
\hline All strength & $82.8(15.4)$ & $81.6(15.9)$ & $1.3(-0.3,2.9)$ & $79.5(13.8)$ & $75.8(14.9)$ & $3.8(1.6,5.9)^{\mathrm{a}}$ \\
\hline $\mathrm{VPT}^{\mathrm{c}}$ digits (microns) & $0.1(0.10)$ & $0.13(0.15)$ & $-0.01(-0.03,0.003)$ & $0.12(0.08)$ & $0.13(0.10)$ & $-0.01(-0.03,0.002)$ \\
\hline VPT radial styloid & $0.5(0.4)$ & $0.5(0.5)$ & $-0.03(-0.1,0.04)$ & $0.5(0.4)$ & $0.5(0.3)$ & $-0.1(-0.1,0.01)$ \\
\hline VPT medial epic. & $0.9(0.9)$ & $0.8(0.9)$ & $0.1(-0.1,0.2)$ & $0.9(0.86)$ & $1.1(1.08)$ & $-0.2(-0.5,0.1)$ \\
\hline $\mathrm{SWM}^{\mathrm{d}}$ web & $20.5(2.7)$ & $20.9(2.6)$ & $-0.4(-1.1,0.3)$ & $20.04(2.42)$ & $20.18(2.30)$ & $-0.2(-0.7,0.4)$ \\
\hline SWM index finger & $20.5(2.4)$ & $21.0(2.28)$ & $-0.5(-1.0,0.03)$ & $20.6(2.67)$ & $20.1(2.9)$ & $0.5(0.04,1.03)^{\mathrm{a}}$ \\
\hline SWM little finger & $21.5(2.5)$ & $22.1(2.2)$ & $-0.6(-1.1,-0.03)^{\mathrm{a}}$ & $21.6(2.6)$ & $21.7(2.7)$ & $-0.1(-0.6,0.5)$ \\
\hline SWM lateral forearm & $20.8(2.5)$ & $21.3(2.1)$ & $-0.5(-1.0,0.1)$ & $20.3(2.2)$ & $19.9(2.9)$ & $0.5(-0.2,1.2)$ \\
\hline SWM medial forearm & $19.8(2.0)$ & $19.8(1.9)$ & $-0.04(-0.5,0.4)$ & $19.3(2.2)$ & $18.6(2.2)$ & $0.7(0.2,1.2)^{\mathrm{a}}$ \\
\hline SWM lateral arm & $20.1(2.3)$ & $20.1(2.5)$ & $-0.04(-0.6,0.5)$ & $19.7(2.2)$ & $19.4(2.2)$ & $0.3(-0.1,0.8)$ \\
\hline SWM medial arm & $19.1(2.5)$ & $18.9(2.6)$ & $0.3(-0.3,0.8)$ & $19.1(2.6)$ & $17.4(3.2)$ & $1.7(0.9,2.5)^{\mathrm{a}}$ \\
\hline Shoulder flexion $\mathrm{ROM}^{\mathrm{e}}$ & $169(8)$ & $166(9)$ & $3.0(1.7,4.5)^{\mathrm{a}}$ & $167(9)$ & $161(12)$ & $6.0(3.9,8.2)^{\mathrm{a}}$ \\
\hline Shoulder ABD ROM & $162(19)$ & $153(25)$ & $9.3(4.8,13.7)^{\mathrm{a}}$ & $158(20)$ & $140(29)$ & $17.5(11.7,23.4)^{\mathrm{a}}$ \\
\hline Shoulder $\mathrm{ER}^{\mathrm{b}} \mathrm{ROM}$ & $93(9)$ & $89(11)$ & $3.7(1.4,6.0)^{\mathrm{a}}$ & $89(10)$ & $86(13)$ & $2.8(0.3,5.3)^{\mathrm{a}}$ \\
\hline Shoulder $\mathrm{IR}^{\mathrm{b}} \mathrm{ROM}$ & $43(9)$ & $42(10)$ & $0.9(-1.1,2.9)$ & $45(9)$ & $44(10)$ & $1.1(-0.9,3.2)$ \\
\hline Elbow flexion ROM & 149 (4) & $150(4)$ & $-0.5(-1.2,-0.2)$ & $150(4)$ & 149 (4) & $0.8(-0.1,1.6)$ \\
\hline Elbow extension ROM & $2(4)$ & $2(4)$ & $0.2(-0.4,0.7)$ & $0.3(5)$ & $0.9(4)$ & $-0.7(-1.4,0.1)$ \\
\hline Wrist flexion ROM & $77(8)$ & $78(7)$ & $-0.6(-2.0,0.8)$ & $77(7)$ & $75(7)$ & $2.0(0.8,3.1)^{\mathrm{a}}$ \\
\hline Wrist extension ROM & $74(7)$ & $73(8)$ & $0.3(-0.8,1.3)$ & $72(7)$ & $71(8)$ & $1.5(-0.1,3.2)$ \\
\hline Index $\mathrm{PIP}^{\mathrm{b}} \mathrm{ROM}$ & $114(6)$ & $114(4)$ & $-0.3(-1.3,0.7)$ & $112(9)$ & $110(7)$ & $1.6(0.01,3.2)^{\mathrm{a}}$ \\
\hline Overall ROM score & $882(40)$ & $866(54)$ & $15.9(8.3,23.4)^{\mathrm{a}}$ & $870(47)$ & $836(62)$ & $32.7(22.2,43.2)^{\mathrm{a}}$ \\
\hline
\end{tabular}

${ }^{\mathrm{a}} p<0.05$

${ }^{\mathrm{b}}$ ABD: abduction; ER: external rotation; IR: internal rotation; PIP: proximal interphalangeal joint

${ }^{\mathrm{c}}$ Vibration perception threshold (in microns)

${ }^{\mathrm{d}}$ Semmes Weinstein Monofilaments (number of correct responses)

${ }^{\mathrm{e}}$ Range of motion (in degrees)

Bold indicates statistical significance

were evaluated to determine if all met the alpha $<0.1$ criterion, and again the one with the highest $p$ value was dropped. This procedure was followed until all predictors in the model were significant at alpha $<0.1$.

The predictors found to significantly contribute to the variance of the DASH scores and be included in the final regression model were past diagnosis of lymphedema $(p<.0 .001)$, grip strength on the affected upper extremity $(p<0.001)$, shoulder abduction ROM on the affected side $(p=0.003)$, and number of comorbidities $(p<0.001)$. This combination of predictors resulted in an $R^{2}$ of 0.463 . Thus, the four predictor variables explained $46.3 \%$ of the variance in the DASH scores (Tables 5 and 6). 


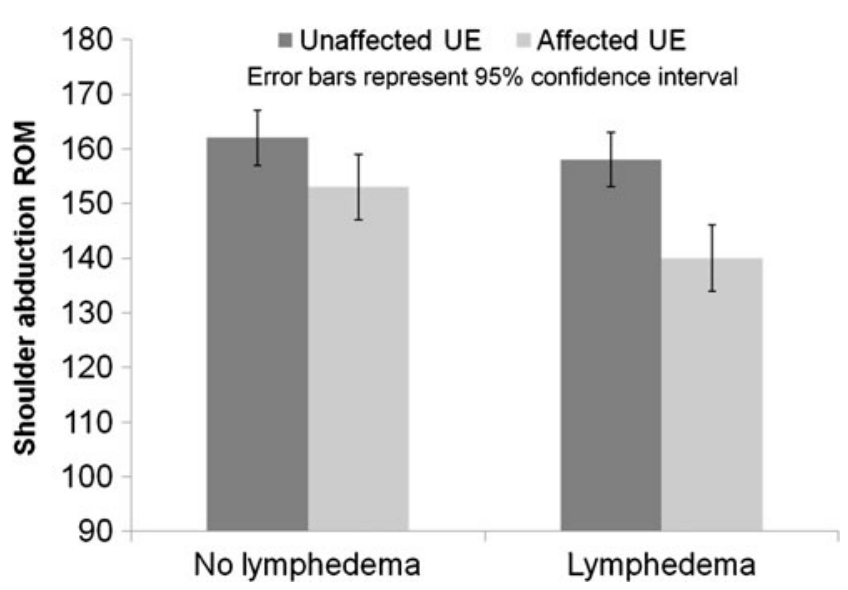

Figure 1 Shoulder abduction range of motion (in degrees).

\section{Discussion}

The results of this study supported our hypotheses. Following breast cancer treatment, upper extremity impairments are present on the side of the breast cancer treatment. Furthermore, our study demonstrates that women with lymphedema demonstrated greater impairments than women without lymphedema.

\section{Range of motion}

Interlimb differences in upper extremity ROM were most notable for shoulder abduction. This finding may indicate a need for early therapeutic intervention to improve upper extremity biomechanics in shoulder elevation in women treated for breast cancer. Our findings are consistent with those of Thomas-MacLean et al. who found both restricted shoulder abduction $\mathrm{ROM}\left(<170^{\circ}\right.$ on the side of treatment $)$ in 205 out of 347 women $6-12$ months following breast cancer treatment, and an interlimb difference of greater than $10^{\circ}$ in $41 \%$ of the women [16]. Deficits in ROM following breast cancer treatment may be the result of postoperative scar tissue formation, radiation-induced fibrosis, protective posturing bringing the shoulders forward, disuse, and/or pain. Limitations in shoulder abduction may interfere with daily activities including reaching behind the head to wash or comb one's hair, or movements requiring maximal shoulder elevation such as reaching items high on a shelf. Our study findings indicated that reductions in shoulder ROM were associated with greater upper extremity disability (higher DASH scores), as became apparent with regression analysis.

Interlimb differences in shoulder abduction were greater in women with lymphedema compared to those without $\left(18^{\circ}\right.$ versus $\left.9^{\circ}\right)$. Our data are in agreement with the findings of Kwan et al. who compared 3 groups of women following breast cancer treatment: those with no upper extremity symptoms $(n=51)$; those with symptoms but no signs of lymphedema $(n=47)$; and those with lymphedema $(n=14)$. Interlimb differences in abduction ROM were $5.9^{\circ}, 19.9^{\circ}$, and $31.1^{\circ}$, respectively [26]. More aggressive breast cancer treatments, such as mastectomy versus breast conserving surgery, and axillary node dissection versus sentinel node biopsy, are associated with greater deficits in shoulder abduction ROM [27-29]. Women who undergo more aggressive treatment for their breast cancer and women who develop lymphedema may require more vigilant musculoskeletal screening following treatment to preserve maximal shoulder elevation.

Strength

Strength differences between the two groups of women were found primarily in elbow flexion. Compared to the women without lymphedema, reduction of elbow flexion strength was seen bilaterally in the women with lymphedema, with the deficit greater on the affected side. Elbow flexion strength was significantly correlated with the DASH item related to carrying objects over $10 \mathrm{lbs}$. Past advice for women with lymphedema included avoidance of lifting or carrying moderately heavy items with the affected upper extremity $[30,31]$. Activity avoidance advice may be a disservice, as upper extremity strength may worsen over time with decreased use, consistent with our findings of reduced elbow flexion and grip strength in women with lymphedema. Though the interlimb difference in grip strength $(1.37 \mathrm{~kg})$ between groups did not reach statistical significance, grip strength did significantly contribute to the variance in DASH scores.

\section{Pain and sensation}

The women with lymphedema more frequently reported upper extremity symptoms such as pain, ache, numbness, or heaviness in the arm. Sensory disturbances in the affected upper extremity following breast cancer treatment may result from nerve damage during surgery or following radiation, neuropathy due to chemotherapy, or perhaps lymphedema. The women with lymphedema demonstrated reduced sensation in the medial arm, which may be the result of trauma to the intercostobrachial or other nerves during axillary node dissection, resulting in subsequent sensory loss. Development of chronic pain following mastectomy has been associated with damage to the intercostobrachial nerve [32]. In the current study, there was a statistically significant but weak correlation between pain and sensory loss; women with less medial arm sensation more frequently reported pain in the upper extremity. However, there was a moderate correlation between breast pain and the DASH $(r=0.50)$ and between 
Table 4 Summary of significance of differences between upper extremities, and differences between groups (Analysis of Variance)

\begin{tabular}{|c|c|c|c|}
\hline & $\begin{array}{l}\text { Within subjects contrasts: main } \\
\text { effect of side } \\
\text { Was the difference between sides } \\
\text { significant, regardless of group? } \\
p\end{array}$ & $\begin{array}{l}\text { Between subjects effects: main effect of } \\
\text { lymphedema } \\
\text { Was the difference between groups } \\
\text { significant, averaged across both arms? } \\
p\end{array}$ & $\begin{array}{l}\text { Interaction effect: side and } \\
\text { lymphedema } \\
\text { Were the differences greater in } \\
\text { the lymphedema group? } \\
p\end{array}$ \\
\hline Purdue Pegboard time(sec) & 0.68 & 0.16 & 0.95 \\
\hline Finger Tapper (no. of taps) & 0.23 & 0.13 & 0.73 \\
\hline Shoulder $\mathrm{ABD}^{\mathrm{b}}$ strength $\mathrm{kg}$ & 0.16 & 0.16 & 0.82 \\
\hline Elbow flexion strength & $0.001^{\mathrm{a}}$ & 0.004 & 0.001 \\
\hline Wrist flexion strength & 0.01 & 0.25 & 0.32 \\
\hline Grip strength & 0.02 & 0.27 & 0.51 \\
\hline Key grip strength & 0.16 & 0.53 & 0.51 \\
\hline 3 point chuck grip & 0.34 & 0.65 & 0.002 \\
\hline All strength & $<0.001$ & 0.06 & 0.07 \\
\hline $\mathrm{VPT}^{\mathrm{c}}$ digits (microns) & 0.03 & 0.69 & 0.98 \\
\hline VPT radial styloid & 0.07 & 0.69 & 0.66 \\
\hline VPT medial epic. & 0.32 & 0.22 & 0.06 \\
\hline $\mathrm{SWM}^{\mathrm{d}}$ web & 0.20 & 0.10 & 0.60 \\
\hline SWM index finger & 0.94 & 0.40 & 0.01 \\
\hline SWM little finger & 0.09 & 0.57 & 0.20 \\
\hline SWM lateral forearm & 1.0 & 0.01 & 0.03 \\
\hline SWM medial forearm & 0.07 & 0.01 & 0.04 \\
\hline SWM lateral arm & 0.42 & 0.09 & 0.30 \\
\hline SWM medial arm & 0.004 & 0.04 & 0.00 \\
\hline Shoulder flexion $\mathrm{ROM}^{\mathrm{e}}$ & $<0.001$ & 0.02 & 0.02 \\
\hline Shoulder abduction ROM & $<0.001$ & 0.01 & 0.03 \\
\hline Shoulder ER ${ }^{\mathrm{b}}$ ROM & $<0.001$ & $\mathbf{0 . 0 3}$ & 0.59 \\
\hline Shoulder $\mathrm{IR}^{\mathrm{b}} \mathrm{ROM}$ & 0.15 & 0.15 & 0.86 \\
\hline Elbow flexion ROM & 0.63 & 0.91 & 0.02 \\
\hline Elbow extension ROM & 0.29 & $\mathbf{0 . 0 3}$ & 0.07 \\
\hline Wrist flexion ROM & 0.14 & 0.13 & 0.01 \\
\hline Wrist extension ROM & 0.07 & 0.12 & 0.20 \\
\hline Index PIP ${ }^{b}$ ROM & 0.16 & 0.01 & 0.05 \\
\hline Overall ROM score & $<0.001$ & 0.01 & 0.01 \\
\hline
\end{tabular}

${ }^{\mathrm{a}} p<0.05$

${ }^{\mathrm{b}}$ ABD: abduction; ER: external rotation; IR: internal rotation; PIP: proximal interphalangeal joint

${ }^{\mathrm{c}}$ Vibration perception threshold (in microns)

${ }^{\mathrm{d}}$ Semmes Weinstein Monofilaments (number of correct responses)

${ }^{\mathrm{e}}$ Range of motion (in degrees)

Bold indicates statistical significance

arm pain and the DASH $(r=0.49)$. In light of this, and that self-reported symptoms of heaviness, numbness, and swelling have been associated with and suggested as possible early indicators for lymphedema [33], lymphedema management should include assessment of pain, heaviness, tightness, or swelling in the affected upper extremity, in addition to circumference measurement. This is supported by published clinical practice guidelines [34].
Body mass index

Body mass index was found to be significantly higher in the women with lymphedema than those without. Twenty-one of the 31 women who had a BMI over 30, and thus would be considered to be "obese", were in the Lymphedema group. These findings are in agreement with extant literature, in which obesity and weight gain following breast cancer 
Change Statistics

\begin{tabular}{|c|c|c|c|c|c|}
\hline \multirow{2}{*}{ Model } & \multirow[b]{2}{*}{$\mathrm{R}$} & \multirow[b]{2}{*}{ R Square } & \\
\hline & & & $\begin{array}{l}\text { R Square } \\
\text { Change }\end{array}$ & F Change & $\begin{array}{l}\text { Sig. F Change } \\
p\end{array}$ \\
\hline 1. Subject diagnosed with lymphedema & .378 & .143 & .143 & 23.269 & .000 \\
\hline 2. Subject diagnosed with lymphedema, grip strength affected side & .592 & .351 & .208 & 44.646 & .000 \\
\hline $\begin{array}{l}\text { 3. Subject diagnosed with lymphedema, grip strength affected side, shoulder } \\
\text { abduction ROM affected side }\end{array}$ & .620 & .385 & .034 & 7.618 & .007 \\
\hline $\begin{array}{l}\text { 4. Subject diagnosed with lymphedema, grip strength affected side, shoulder } \\
\text { abduction ROM affected side, Number of comorbidities }\end{array}$ & .681 & .463 & .078 & 19.977 & .000 \\
\hline
\end{tabular}

treatment have been associated with the development of lymphedema [35]. There is also evidence that high BMI and lack of vigorous physical activity may be associated with increased breast cancer risk [36]. Furthermore, it is well known that high BMI is associated with increased risk of chronic diseases such as cardiovascular disease and diabetes. These findings suggest that weight management may be an important component of rehabilitation following breast cancer treatment to aid in the prevention and management of lymphedema, as well as to reduce the risk of cancer recurrence and the development of other chronic illnesses.

\section{DASH}

Women with a previous diagnosis of lymphedema scored higher on the DASH, indicating greater limitation in upper extremity activities compared to the women without a history of lymphedema. Although the DASH scores for the women in this study indicated a relatively high selfreported level of upper extremity physical function, there was a statistically significant difference (10 points) between the Lymphedema and Non-lymphedema groups. A 10-point difference has been suggested as the minimal important change in DASH scores following treatment of upper extremity musculoskeletal impairments [22].

Our findings are consistent with those of Dawes et al. who examined scores for the DASH questionnaire for a group of women following breast cancer surgery. Of the 204 respondents, 72 (35\%) reported more than one symptom associated with lymphedema. These women had significantly higher scores on the DASH compared to non-symptomatic women, indicative of greater limitations in upper extremity function. Clinical assessment of a sample of 50 of the women with lymphedema symptoms yielded statistically significant compromise in manual dexterity, grip strength, and scores on the Medical Outcome Study Short Form 36 Physical Component Scale [37]. We found similar impairments in strength in the women in our study.

Grip strength and shoulder abduction ROM on the affected side, number of comorbidities, and previous diagnosis of lymphedema significantly contributed to the variance in the DASH scores. Interestingly, in spite of the contribution of past diagnosis of lymphedema, neither arm volume (calculated from circumference) nor impedance ratios (from bioimpedance spectroscopy) contributed to the variance in the DASH scores. This finding is also consistent with the findings of Dawes et al. [37].

Most of the women in the Lymphedema group had mild lymphedema. Only four women had volume differences greater than $750 \mathrm{ml}$. This is consistent with the distribution of lymphedema categories in the 3 year incidence of lymphedema found by Norman et al. [11], and may be reflective of lymphedema severity in the general breast cancer-related lymphedema population. Furthermore, all but seven of the women in our study who were previously diagnosed with lymphedema had received lymphedema treatment. Previous treatment included education, compression, remedial exercise, manual lymph drainage, bandaging, and instruction in self care and management. It is possible

Table 6 Coefficients table

\begin{tabular}{|c|c|c|c|c|c|c|}
\hline & $\mathrm{B}$ & Std. error & Beta & $\mathrm{t}$ & Sig & $95 \% \mathrm{CI}$ for $\mathrm{B}$ \\
\hline (Constant) & .466 & 699 & & 0.668 & 0.51 & $-.915,1.848$ \\
\hline subject diagnosed with lymphedema & .911 & .212 & .277 & 4.302 & $<.001$ & $.492,1.330$ \\
\hline shoulder abduction ROM affected side & -.012 & .004 & -.202 & -3.072 & 0.003 & $-.020,-.004$ \\
\hline grip strength affected side & -.038 & .007 & -.341 & -5.099 & $<.001$ & $-.052,-.023$ \\
\hline Number of comorbidities & .320 & .072 & .291 & 4.470 & $<.001$ & $.178, .461$ \\
\hline
\end{tabular}


these women chose to limit use of the affected upper extremity as part of the lymphedema management, regardless of current limb volume. This behavior of limited use may have contributed to higher DASH scores in this group. Actual volume of lymphedema does not explain concurrent functional arm limitation and may not be reflective of the true impact of chronic lymphedema.

Overall, the women in this study demonstrated relatively low scores on the DASH in spite of significant upper extremity impairments. This suggests that upper extremity impairment does not necessarily preclude women from achieving a fairly high level of activity. While working to restore strength and range of motion, rehabilitation professionals can also guide and encourage return to safe activity following breast cancer treatment in spite of these limitations.

Correlation between the DASH and objective measures of upper extremity physical impairments and limitations were variable, from poor to moderate. The highest correlations were found for shoulder abduction ROM and strength, elbow flexion strength, and grip strength, on the affected side ( $r=0.35$ to 0.50$)$. As previously noted, pain in the breast and arm were also moderately correlated with the DASH. With these relatively modest correlations, it appears that factors other than range of motion and strength influence actual task performance. We did not find significant correlations between the DASH and demographic variables such as age, or body mass index, nor current work or exercise history. Inclusion of objective measurement and self report of physical limitations may help direct clinical decision making and referral to appropriate health care providers. Those patients with self report of physical activity limitations, without any evidence of pain or objective physical impairments, may benefit from further assessment or referral to a behavioral health specialist.

Our study highlights the degree of upper extremity impairment, and the impact of these impairments, medical comorbidities, and lymphedema on upper extremity physical function in women following breast cancer treatment, and underscores the need for increased exercise and physical activity in this group. Studies of exercise interventions are beginning to emerge in the literature. Ahmed et al., in a randomized controlled trial of women with and without breast-cancer-related lymphedema, compared twice weekly weight training $(n=23)$ to a non-exercise control group $(n=22)$. The gradually progressive strengthening program resulted in significantly improved bench press strength in the exercise group, and there was no evidence of new or worsening lymphedema [30]. More recently, 32 women with breast-cancer-related lymphedema participated in a single blind randomized control study designed to evaluate the effects of aerobic and weight training exercises on lymphedema. Exercise did not exacerbate lymphedema, and two of the women in the exercise group had no evidence of lymphedema at the conclusion of the study [15]. These recent studies suggest that increased activity and exercise is beneficial and safe for women with breastcancer-related lymphedema.

\section{Limitations}

We provide evidence that lymphedema is associated with greater reduction in upper extremity mobility, strength, and sensation. However, due to the cross sectional design employed in this study, we cannot conclude that the presence of lymphedema was the cause of these reductions.

The DASH has been used previously as a measure of upper extremity function in women with breast cancer; however, the DASH has not as yet been validated in this group. The DASH had a floor effect in our study, which may have influenced the responsiveness of the instrument to differences in higher functioning women who occupy the lower range of scores on the scale.

While we did find a significant difference in DASH scores between groups, perhaps a more responsive instrument would highlight more subtle differences in the higher functioning participants. The correlations were low to moderate (between -0.18 and -0.50 in the present study) between objective measures of physical impairments such as ROM, strength, fine motor coordination and the selfreport measures of physical symptoms and functional activities (i.e., the DASH). These findings are consistent with the results of other investigators [38, 39]. Performance of functional tasks is influenced by psychosocial and environmental factors, not all of which were addressed in the present study. It appears that self report and objective measures of upper extremity physical impairments and performance activities may not be entirely, or exclusively, reflective of one another and both may need to be included for optimal assessment of physical function. Further investigation of upper extremity physical functioning questionnaires for use in this population is warranted.

\section{Conclusion}

Our study indicates that following breast cancer treatment, women with and without lymphedema present with upper extremity impairments. Women with lymphedema more frequently report pain, demonstrate bilateral impairments in shoulder ROM and upper extremity strength compared to women without lymphedema, and present with greater restrictions in upper limb activities. Each of these limitations is amenable to rehabilitation interventions. Based on the results of this study, physical rehabilitation should be included in the management of sequelae following breast 
cancer treatment. Assessment and treatment of breast cancer survivors should address limb volume (and volume changes), bilateral upper extremity ROM and strength, sensation and pain, body mass index, and presence of other medical comorbidities. It is important to keep in mind that complications from breast cancer treatment, such as lymphedema and fibrosis, may not be apparent for months to years after the end of the cancer treatment. In light of the growing numbers of breast cancer survivors, and the likelihood for the development of impairments and activity limitations post cancer treatment, it is imperative for health care providers, particularly physical and occupational therapists, to be aware of the unique problems faced by this population and advocate for prevention and evidencebased intervention.

Acknowledgments The authors would like to thank Jane Armer, RN, $\mathrm{PhD}$, Saskia Thiadens, RN, Maria Cho, RN, PhD, Diane Allen PT, PhD, and Marc Hurlbert, $\mathrm{PhD}$, for their support, assistance, and valuable input. This research was supported by a grant from the National Institute of Nursing Research (NIH 1R21 NR0101282U) and by NIH/NCRR UCSFCTSI Grant Number UL1 RR024131. Its contents are solely the responsibility of the author and do not necessarily represent the official views of the National Institutes of Health.

Open Access This article is distributed under the terms of the Creative Commons Attribution Noncommercial License which permits any noncommercial use, distribution, and reproduction in any medium, provided the original author(s) and source are credited.

\section{References}

1. Jemal A, Siegel R, Ward E, Murray T, Xu J, Smigal C, et al. Cancer statistics, 2006. CA Cancer J Clin. 2006;56:106-30.

2. Smigal C, Jemal A, Ward E, Cokkinides V, Smith R, Howe HL, et al. Trends in breast cancer by race and ethnicity: update 2006. CA Cancer J Clin. 2006;56:168-83.

3. Bani HA, Fasching PA, Lux MM, Rauh C, Willner M, Eder I, et al. Lymphedema in breast cancer survivors: assessment and information provision in a specialized breast unit. Patient Educ Couns. 2007;66:311-8.

4. de Jong N, Candel MJ, Schouten HC, Abu-Saad HH, Courtens AM. Prevalence and course of fatigue in breast cancer patients receiving adjuvant chemotherapy. Ann Oncol. 2004;15:896-905.

5. Jansen CE, Miaskowski C, Dodd M, Dowling G, Kramer J. A metaanalysis of studies of the effects of cancer chemotherapy on various domains of cognitive function. Cancer 2005;104:222233.

6. Wampler MA, Miaskowski C, Hamel K, Byl N, Rugo H, Topp K. The modified total neuropathy score: a clinically feasible and valid measure of taxane-induced peripheral neuropathy in women with breast cancer. J Support Oncol. 2006;4:9-16.

7. Steegers MA, Wolters B, Evers AW, Strobbe L, Wilder-Smith OH. Effect of axillary lymph node dissection on prevalence and intensity of chronic and phantom pain after breast cancer surgery. J Pain. 2008;9:813-22.

8. Calitchi E, Kirova YM, Otmezguine Y, Feuilhade F, Piedbois Y, Le Bourgeois JP. Long-term results of neoadjuvant radiation therapy for breast cancer. Int J Cancer. 2001;96:253-9.
9. Fehlauer F, Tribius S, Holler U, Rades D, Kuhlmey A, Bajrovic A, et al. Long-term radiation sequelae after breast-conserving therapy in women with early-stage breast cancer: an observational study using the LENT-SOMA scoring system. Int J Radiat Oncol Biol Phys. 2003;55:651-8.

10. Leidenius M, Leppanen E, Krogerus L, von Smitten K. Motion restriction and axillary web syndrome after sentinel node biopsy and axillary clearance in breast cancer. Am J Surg. 2003;185:12730.

11. Norman SA, Localio AR, Potashnik SL, Simoes Torpey HA, Kallan MJ, Weber AL, et al. Lymphedema in breast cancer survivors: incidence, degree, time course, treatment, and symptoms. J Clin Oncol. 2009;27:390-7.

12. McLaughlin SA, Wright MJ, Morris KT, Giron GL, Sampson MR, Brockway JP, et al. Prevalence of lymphedema in women with breast cancer 5 years after sentinel lymph node biopsy or axillary dissection: objective measurements. J Clin Oncol. 2008;26:5213-9.

13. Mortimer PS. The pathophysiology of lymphedema. Cancer 1998;83:2798-802.

14. Hayes SC, Janda M, Cornish B, Battistutta D, Newman B. Lymphedema after breast cancer: incidence, risk factors, and effect on upper body function. J Clin Oncol. 2008;26:3536-42.

15. Hayes SC, Reul-Hirche H, Turner J. Exercise and secondary lymphedema: safety, potential benefits, and research issues. Med Sci Sports Exerc. 2009;41:483-9.

16. Thomas-Maclean RL, Hack T, Kwan W, Towers A, Miedema B, Tilley A. Arm morbidity and disability after breast cancer: new directions for care. Oncol Nurs Forum. 2008;35:65-71.

17. Brach M, Cieza A, Stucki G, Fussl M, Cole A, Ellerin B, et al. ICF core sets for breast cancer. J Rehabil Med. 2004;(44 Suppl):121-7.

18. Cheville AL, Troxel AB, Basford JR, Kornblith AB. Prevalence and treatment patterns of physical impairments in patients with metastatic breast cancer. J Clin Oncol. 2008;26:2621-9.

19. Norkin CC, White DJ. Measurement of joint motion, a guide to goniometry. 3rd ed. Philadelphia: FA Davis; 2003.

20. Sander AP, Hajer NM, Hemenway K, Miller AC. Upper-extremity volume measurements in women with lymphedema: a comparison of measurements obtained via water displacement with geometrically determined volume. Phys Ther. 2002;82:1201-12.

21. Waeber M, Castiglione-Gertsch M, Dietrich D, Thurlimann B, Goldhirsch A, Brunner KW, et al. Adjuvant therapy after excision and radiation of isolated postmastectomy locoregional breast cancer recurrence: definitive results of a phase III randomized trial (SAKK 23/82) comparing tamoxifen with observation. Ann Oncol. 2003; 14:1215-21.

22. Gummesson C, Atroshi I, Ekdahl C. The disabilities of the arm, shoulder and hand (DASH) outcome questionnaire: longitudinal construct validity and measuring self-rated health change after surgery. BMC Musculoskelet Disord. 2003;4:11.

23. Beaton DE, Katz JN, Fossel AH, Wright JG, Tarasuk V, Bombardier C. Measuring the whole or the parts? Validity, reliability, and responsiveness of the disabilities of the arm, shoulder and hand outcome measure in different regions of the upper extremity. J Hand Ther. 2001;14:128-46.

24. Dixon D, Johnston M, McQueen M, Court-Brown C. The Disabilities of the Arm, Shoulder and Hand Questionnaire (DASH) can measure the impairment, activity limitations and participation restriction constructs from the International Classification of Functioning, Disability and Health (ICF). BMC Musculoskelet Disord. 2008;9:114.

25. Hayes S, Battistutta D, Newman B. Objective and subjective upper body function six months following diagnosis of breast cancer. Breast Cancer Res Treat. 2005;94:1-10.

26. Kwan W, Jackson J, Weir LM, Dingee C, McGregor G, Olivotto IA. Chronic arm morbidity after curative breast cancer treatment: 
prevalence and impact on quality of life. J Clin Oncol. 2002;20:42428.

27. Rietman JS, Geertzen JH, Hoekstra HJ, Baas P, Dolsma WV, de Vries J, et al. Long term treatment related upper limb morbidity and quality of life after sentinel lymph node biopsy for stage I or II breast cancer. Eur J Surg Oncol. 2006;32:148-52.

28. Lauridsen MC, Overgaard M, Overgaard J, Hessov IB, Cristiansen P. Shoulder disability and late symptoms following surgery for early breast cancer. Acta Oncol. 2008;47:569-75.

29. Nesvold IL, Dahl AA, Lokkevik E, Marit Mengshoel A, Fossa SD. Arm and shoulder morbidity in breast cancer patients after breast-conserving therapy versus mastectomy. Acta Oncol. 2008;47:835-42.

30. Ahmed RL, Thomas W, Yee D, Schmitz KH. Randomized controlled trial of weight training and lymphedema in breast cancer survivors. J Clin Oncol. 2006;24:2765-72.

31. Harris SR, Niesen-Vertommen SL. Challenging the myth of exercise-induced lymphedema following breast cancer: a series of case reports. J Surg Oncol. 2000;74:95-8. discussion 98-9.

32. Torresan RZ, Cabello C, Conde DM, Brenelli HB. Impact of the preservation of the intercostobrachial nerve in axillary lymphadenectomy due to breast cancer. Breast J. 2003;9:389-92.
33. Armer JM, Radina ME, Porock D, Culbertson SD. Predicting breast cancer-related lymphedema using self-reported symptoms. Nurs Res. 2003;52:370-9.

34. Harris SR, Hugi MR, Olivotto IA, Levine M. Clinical practice guidelines for the care and treatment of breast cancer: 11 . Lymphedema. CMAJ 2001;164:191-9.

35. Vignes S, Arrault M, Dupuy A. Factors associated with increased breast cancer-related lymphedema volume. Acta Oncol. 2007;46:1138-42.

36. Silvera SA, Jain M, Howe GR, Miller AB, Rohan TE. Energy balance and breast cancer risk: a prospective cohort study. Breast Cancer Res Treat. 2006;97:97-106.

37. Dawes DJ, Meterissian S, Goldberg M, Mayo NE. Impact of lymphoedema on arm function and health-related quality of life in women following breast cancer surgery. J Rehabil Med. 2008;40:651-8.

38. Thomas-MacLean R, Miedema B, Tatemichi SR. Breast cancerrelated lymphedema: women's experiences with an underestimated condition. Can Fam Physician. 2005;51:246-7.

39. Simmonds MJ. Physical function in patients with cancer: psychometric characteristics and clinical usefulness of a physical performance test battery. J Pain Symptom Manag. 2002;24:404-14. 